\title{
Desempenho, características de carcaça e avaliação econômica da substituição do milho grão inteiro por casca de soja peletizada na alimentação de cordeiros em confinamento ${ }^{1}$
}

\author{
Performance, carcass traits and economic evaluation of the \\ replacement of corn whole grain by pelleted soybean hulls in the \\ feeding of feedlot lambs
}

\author{
Tiago Galafassi Zarpelon²; Ivone Yurika Mizubuti ${ }^{3,1 *}$; \\ Edson Luis de Azambuja Ribeiro ${ }^{3,1}$; Elzânia Sales Pereira'; \\ Leandro das Dores Ferreira da Silva ${ }^{3}$; Odimári Pricila Prado-Calixto ${ }^{3}$; \\ Marina Avena Tarsitano ${ }^{5}$; Ricardo Fávero ${ }^{5}$; Kássia Amariz Pires ${ }^{5}$; \\ César Aparecido de Araújo Borges ${ }^{2}$
}

\begin{abstract}
Resumo
Este trabalho foi conduzido com o objetivo de avaliar os efeitos de diferentes níveis de substituição do milho inteiro por casca de soja peletizada, em rações com alto teor de concentrados, sem utilização de fibra longa, sobre o consumo, desempenho produtivo e viabilidade econômica da produção de cordeiros em confinamento. Foram utilizados 24 ovinos da raça Texel, sendo 12 machos inteiros e 12 fêmeas da mesma idade, com peso médio inicial de $23 \mathrm{~kg}$, distribuídos em 12 baias, em delineamento experimental inteiramente casualizado. Os tratamentos consistiram de substituições do milho inteiro pela casca de soja, nos níveis de $0 \%(\mathrm{CS} 0), 15 \%$ (CS15) e 30\% (CS30). Os consumos de matéria seca (MS) ( $\left.\mathrm{kg} \mathrm{dia}^{-1}\right)$, proteína bruta (PB) $\left(\mathrm{kg} \mathrm{dia}^{-1}, \% \mathrm{PV}, \mathrm{g} \mathrm{PV}{ }^{0,75}\right.$ ) e fibra em detergente neutro (FDN) ( $\mathrm{kg} \mathrm{dia}^{-1}, \% \mathrm{PV}, \mathrm{g} \mathrm{PV}^{0,75}$ ), apresentaram comportamento linear crescente $(\mathrm{P}<0,05)$ à medida que se aumentou a inclusão de casca de soja em substituição ao milho inteiro na ração, entretanto, o consumo de extrato etéreo (EE) ( $\mathrm{g}$ dia $\left.^{-1}\right)$ apresentou efeito quadrático. Não houve diferença significativa no consumo de MS em relação ao peso vivo e tamanho metabólico, bem como para os consumos de matéria mineral (MM) (g dia $\left.{ }^{-1}\right)$ e NDT ( $\mathrm{kg} \mathrm{dia}$ $\left.{ }^{1}, \% \mathrm{PV}, \mathrm{g} \mathrm{PV} \mathrm{PV}^{0,75}\right)$. No ganho médio diário (GMD) foi observado efeito quadrático $(\mathrm{P}<0,05)$ dos diferentes níveis de casca de soja nas rações sendo os ganhos de 0,$267 ; 0,327$ e $0,224 \mathrm{~kg} \mathrm{dia}^{-1}$, nos níveis de 0,15 e $30 \%$, respectivamente. A conversão alimentar foi afetada de forma linear crescente $(\mathrm{P}<0,05)$ com a inclusão de casca de soja na ração. Não foi observada diferença significativa nas características de carcaça. Conforme níveis crescentes de casca de soja foram adicionados à ração, observou-se que houve diminuição do custo/kg MS da ração (R\$), porém houve aumento no custo do quilograma de carne produzida. De maneira geral, pode-se concluir que a substituição do milho inteiro por casca de soja peletizada em rações completas com alto teor de concentrados, na proporção de $15 \%$, aumenta o ganho de peso de cordeiros em
\end{abstract}

\footnotetext{
${ }^{1}$ Parte da Dissertação de Mestrado do primeiro autor

2 Zootecnistas, M.e em Ciência Animal. E-mail: tiago.nutron@gmail.com; cesar.nutron@gmail.com

${ }^{3}$ Profs. Drs., Dept ${ }^{\circ}$ de Zootecnia, Centro de Ciências Agrárias, Universidade Estadual de Londrina, UEL, Londrina, PR. ${ }^{3,1}$ Bolsistas de Produtividade do CNPq. E-mail: mizubuti@uel.br; elar@uel.br; leandro@uel.br; odimari@uel.br

${ }^{4}$ Prof $^{\mathrm{a}} \mathrm{Dr}^{\mathrm{a}}$, Dept ${ }^{\mathrm{o}}$ de Zootecnia, Centro de Ciências Agrárias, Universidade Federal do Ceará, UFC, Fortaleza, CE. Bolsista de Produtividade do CNPq. E-mail: elzania@hotmail.com

5 Discentes do Curso de Doutorado do Programa de Pós-Graduação em Ciência Animal, UEL, Londrina, PR. E-mail: marina_ avena@yahoo.com.br; ricardo.mvet@yahoo.com.br; kassia.amariz@gmail.com

* Autor para correspondência
} 
confinamento e na proporção de 30\% afeta negativamente o desempenho animal, contudo não influencia as características de carcaça. Rações sem inclusão de casca de soja produz carne com menor custo.

Palavras-chave: Conversão alimentar, ganho de peso, ruminantes

\begin{abstract}
This work was carried out with the objective of evaluating the effects of different levels of replacement of whole grain corn by pelleted soybean hulls in high concentrated diet, without long fiber use, on intake, productive performance and economical viability of feedlot lambs production. Twenty four Texel lambs, 12 males and 12 females of the same age, with average weight of $23 \mathrm{~kg}$, distributed in 12 stalls, in a completely randomized design, were used. The treatments consisted of replacement of whole grain corn by pelleted soybean hulls, at levels of $0 \%$ (SH0), 15\% (SH15) and 30\% (SH30). Dry matter (DM) (kg day $\left.^{-1}\right)$, crude protein $(\mathrm{CP})\left(\mathrm{kg} \mathrm{day}^{-1}, \% \mathrm{AW}, \mathrm{g} \mathrm{AW}^{0,75}\right)$, and neutral detergent fiber (NDF) (kg day ${ }^{-1}, \% \mathrm{AW}, \mathrm{g}$ $\left.\mathrm{AW}^{0,75}\right)$ intake showed linear increasing behavior $(\mathrm{P}<0.05)$ according to increasing levels of soybean hulls replacing the corn grain in the diet, however, the ether extract (EE) intake $\left(\mathrm{g} \mathrm{day}^{-1}\right)$ presented quadratic effect. There were no differences in DM intake in relation to weight and metabolic body size, as well as, to mineral material $(\mathrm{MM})\left(\mathrm{g} \mathrm{day}^{-1}\right)$ and total digestible nutrients $(\mathrm{TDN})$ intake $\left(\mathrm{kg} \mathrm{day}^{-1}, \% \mathrm{AW}, \mathrm{g} \mathrm{AW}^{0,75}\right)$. In average daily gain (ADG), a quadratic effect of different levels of soybean hulls in the diet was observed $(\mathrm{P}<0.05)$, with weight gain of $0.267 ; 0.327$ and $0.224 \mathrm{~kg}$ day $^{-1}$, in levels of 0,15 and $30 \%$, respectively. The feed conversion was affected in a increasing linear way $(\mathrm{P}<0.05)$ with the soybean hulls inclusion in the diet. It was not observed differences in the carcass traits. When increasing levels of soybean hulls were added to the diet, it was observed decreasing in cost $/ \mathrm{kg}$ ration $(\mathrm{R} \$)$, however, there was increasing cost of meat produced $(\mathrm{kg})$. In a general way, it can be concluded that replacement of whole corn by pelleted soybean hulls in high concentrated diet, in a proportion of $15 \%$, increases the weight gain in feedlot lambs. In the proportion of $30 \%$, affect negatively the animal performance, however does not influence the carcass traits. Diets without soybean hulls produce meat $(\mathrm{kg})$ at lower cost.
\end{abstract}

Key words: Feed conversion, ruminants, weight gain

\section{Introdução}

O aumento na demanda de carne ovina de boa qualidade tem gerado a necessidade de intensificar a produção para abastecimento continuo no mercado. O confinamento de cordeiros pode ser uma alternativa viável no sentido de produzir carne de boa qualidade, e diminuir a idade de abate dos animais, além de diminuir a competição por área de solo com outras atividades agrícola e pecuária.

Segundo Pordomingo et al. (2002), a inclusão de cascas de sementes em rações sem fonte de volumosos, pode diminuir o risco de acidose e melhorar o desempenho animal devido à grande quantidade de fibra contida nestes ingredientes. Além disto, relataram que a substituição de volumosos por subprodutos fibrosos diminui o custo por unidade de energia digestível devido a maior densidade energética destes ingredientes.
O processo de extração de óleo do grão de soja produz além do farelo, cerca de $2 \%$ de casca, podendo variar de $0 \%$ a $3 \%$, de acordo com o teor de proteína da soja esmagada (ZAMBOM et al., 2001). Em geral, a casca de soja apresenta alto valor nutricional, com teores de $13,0 \%$ de proteína bruta, $2,6 \%$ de extrato etéreo, $77,0 \%$ de nutrientes digestíveis totais, $62,0 \%$ de fibra em detergente neutro e $46 \%$ de fibra insolúvel em detergente ácido, na matéria seca (NRC, 2007).

Este subproduto apresenta elevado teor de FDN altamente digestível, e quando utilizada em rações de alto teor de concentrado, substituindo o milho, pode aumentar o $\mathrm{pH}$ ruminal devido à modificação no padrão de fermentação ruminal (FERREIRA et al., 2008). A casca de soja possui valor energético inferior à do milho, cujos valores são de 3,4 Mcal e 3,6 Mcal, respectivamente. Entretanto, devido 
ao alto teor de fibra em detergente neutro de alta digestibilidade (NRC, 2007), seu padrão de fermentação ruminal leva à maior produção de ácido acético e menor produção de lactato, diminuindo os riscos de acidose (LUDDEN; CECAVA; HENDRIX, 1995).

O processo de peletização da casca de soja aumenta a densidade do alimento, melhora a digestibilidade dos nutrientes e a palatabilidade da ração, bem como o seu consumo. A peletização diminui a perda de ração pelo animal e facilita o manejo durante o transporte e alimentação evitando o processo de seleção de alimentos no cocho (GADIENT, 1986).

Observa-se na literatura que existem diversos experimentos avaliando a substituição de alimentos concentrados pela casca de soja, entretanto, são pouco disponíveis os trabalhos utilizando casca de soja peletizada. Portanto, este trabalho teve como objetivo avaliar os efeitos da substituição do milho inteiro por casca de soja peletizada em rações, sem fibra longa, sobre o consumo de nutrientes, desempenho produtivo e viabilidade econômica da produção de cordeiros em confinamento.

\section{Material e Métodos}

O experimento foi conduzido na fazenda escola da Universidade Estadual de Londrina. Foram utilizados 24 ovinos da raça Texel, sendo 12 machos inteiros e 12 fêmeas da mesma idade, com peso médio inicial de $23 \mathrm{~kg}$, distribuídos em 12 baias e alojando-se dois animais de gêneros distintos por baias. As baias continham área útil de $2,5 \mathrm{~m}^{2}$, piso de concreto, bebedouro e cocho de alimentação coletiva com densidade de $20 \mathrm{~cm} /$ animal.

$\mathrm{O}$ delineamento experimental utilizado foi o inteiramente casualizado com três tratamentos, sendo 0\% (CS0), 15\% (CS15) e 30\% (CS30) de substituição do milho inteiro por casca de soja peletizada, e oito repetições (quatro machos e quatro fêmeas). Durante sete dias os animais permaneceram em adaptação com oferta de feno de Tifton, à vontade, e quantidades diárias crescentes das dietas experimentais. Após este período, os animais receberam exclusivamente as rações experimentais, sem feno (Tabela 1). Para determinação do consumo de nutrientes e desempenho dos animais foi utilizado um período de quarenta e dois dias, após o período de adaptação.

As rações experimentais continham os seguintes ingredientes: milho grão inteiro seco, casca de soja peletizada e concentrado proteico contendo: farelo de soja, uréia, núcleo mineral-vitamínico e aditivo promotor de crescimento. As proporções dos ingredientes e a composição química das rações encontram-se nas Tabelas 1 e 2, respectivamente.

Tabela 1. Composição percentual dos ingredientes nas rações experimentais na matéria natural.

\begin{tabular}{lccc}
\hline \multicolumn{1}{c}{ Ingredientes } & \multicolumn{3}{c}{$\begin{array}{c}\text { Rações experimentais } \\
\text { (Níveis de substituição) }\end{array}$} \\
\cline { 2 - 4 } & $\mathrm{CS} 0(0 \%)$ & $\mathrm{CS} 15(15 \%)$ & $\mathrm{CS} 30(30 \%)$ \\
\hline Milho grão inteiro & 85,0 & 70,0 & 55,0 \\
Casca de soja peletizada & 0 & 15,0 & 30,0 \\
Concentrado protéico, mineral e vitamínico & 15,0 & 15,0 & 15,0 \\
\hline Total & 100,00 & 100,00 & 100,00 \\
\hline
\end{tabular}

CS0, CS15 e CS30 correspondem às rações cujas substituições do milho inteiro pela casca de soja foram de 0 , 15 e $30 \%$, respectivamente.

Fonte: Elaboração dos autores. 
Os alimentos foram fornecidos à vontade, duas vezes ao dia, às 7:30 e às 17:30 horas, sendo que as sobras foram registradas e pesadas diariamente para a determinação do consumo diário. A quantidade de ração fornecida foi calculada de modo a permitir aproximadamente $15 \%$ de sobras, enquanto o fornecimento de água foi à vontade.
Semanalmente foram coletadas amostras das rações experimentais ofertadas que foram agrupadas proporcionalmente, constituindo-se as amostras compostas. O mesmo processo foi utilizado para as sobras. Estas amostras foram secas em estufa a $55^{\circ} \mathrm{C}$ e moídas em moinhos tipo Willey com peneiras de $1 \mathrm{~mm}$ para posterior análise.

Tabela 2. Composição bromatológica dos ingredientes e das rações experimentais.

\begin{tabular}{|c|c|c|c|c|c|c|}
\hline & $\begin{array}{l}\text { Milho grão } \\
\text { inteiro }\end{array}$ & $\begin{array}{c}\text { Casca de } \\
\text { soja }\end{array}$ & Concentrado $^{1}$ & CS0 & CS15 & $\mathrm{CS} 30$ \\
\hline Matéria seca $\left(\mathrm{g} \mathrm{kg}^{-1}\right)$ & 880,6 & 900,2 & 893,6 & 889,5 & 891,3 & 883,5 \\
\hline Nutrientes digestíveis totais $\left(\mathrm{g} \mathrm{kg}^{-1} \mathrm{MS}\right)$ & 814,4 & 593,6 & 635,2 & 789,7 & 754,8 & 721,2 \\
\hline Proteina bruta $\left(\mathrm{g} \mathrm{kg}^{-1} \mathrm{MS}\right)$ & 88,5 & 130,1 & 362,3 & 121,8 & 133,8 & 135,2 \\
\hline Extrato etéreo $\left(\mathrm{g} \mathrm{kg}^{-1} \mathrm{MS}\right)$ & 39,7 & 28,9 & 25,0 & 38,2 & 35,8 & 28,8 \\
\hline Fibra em detergente neutro (FDN) $\left(\mathrm{g} \mathrm{kg}^{-1} \mathrm{MS}\right)$ & 95,2 & 727,4 & 155,5 & 103,6 & 205,9 & 302,7 \\
\hline FDN efetiva ${ }^{2}\left(\mathrm{~g} \mathrm{~kg}^{-1} \mathrm{MS}\right)$ & 1000,0 & 20,0 & - & 80,7 & 79,4 & 56,6 \\
\hline Amido $\left(\mathrm{g} \mathrm{kg}^{-1} \mathrm{MS}\right)$ & 690,0 & 29,0 & 110,0 & 603,0 & 503,8 & 404,7 \\
\hline Matéria mineral $\left(\mathrm{g} \mathrm{kg}^{-1} \mathrm{MS}\right)$ & 11,0 & 45,2 & 222,0 & 36,1 & 35,0 & 54,6 \\
\hline Monensina Sódica ${ }^{3}(\mathrm{ppm})$ & - & - & 166,66 & 25,41 & 25,41 & 25,41 \\
\hline
\end{tabular}

CS0, CS15 e CS30 correspondem às rações cujas substituições do milho inteiro pela casca de soja foram de 0 , 15 e $30 \%$, respectivamente.

${ }^{1}$ Composição do concentrado proteico, mineral e vitamínico: Vitamina A 33.330,00 UI kg ${ }^{-1}$; Vitamina D3 $2.220,00$ UI kg ${ }^{-1}$; Vitamina E 138,88 UI kg ${ }^{-1}$; Cálcio 56,1 $\mathrm{g} \mathrm{kg}^{-1} \mathrm{MS}$; Fósforo 11,1 $\mathrm{g} \mathrm{kg}^{-1} \mathrm{MS}$; Enxofre 50,0 $\mathrm{g} \mathrm{kg}^{-1} \mathrm{MS}$; Sódio 94,4 g kg-1 MS; Cloro 147,7 $\mathrm{g} \mathrm{kg}^{-1} \mathrm{MS}$; Manganês 277,7 mg kg-1; Cobre 91,11 mg kg-1; Iodo 4,97 mg kg-1; Zinco 360,00 mg kg-1; Cobalto 4,97 mg kg-1; Selênio $1,53 \mathrm{mg} \mathrm{kg}^{-1}$.

${ }^{2}$ Calculado considerando-se a efetividade da fibra em detergente neutro do milho inteiro $=100 \%$ e da casca de soja $=2 \%$, multiplicado pelo seu valor FDN e pela sua inclusão na ração, segundo NRC (1985).

${ }^{3}$ Calculado com base nos níveis de garantia do concentrado protéico, mineral e vitamínico multiplicado pela sua inclusão na ração. Fonte: Elaboração dos autores.

As pesagens dos animais foram realizadas no inicio do experimento e a cada 14 dias, após jejum de sólidos de 12 horas, completando três pesagens durante o período experimental. A partir desses dados foram calculados o ganho médio diário (GMD), a matéria seca ingerida (MSI), a matéria seca ingerida/100 $\mathrm{kg}$ de peso vivo (MS\%PV), a matéria seca ingerida $/ \mathrm{kg}^{0,75}\left(\mathrm{MSIkg}^{0,75}\right)$ e a conversão alimentar (CA) (ganho médio diário/matéria seca ingerida).

Após 42 dias de experimento os animais foram submetidos ao manejo pré-abate. Os animais foram pesados após jejum de sólidos de 12 horas, para permitir posterior determinação de rendimento de carcaça. Os cordeiros foram transportados para um frigorífico comercial a $45 \mathrm{~km}$ de Londrina-PR e foram abatidos seguindo a legislação de abate humanitário (BRASIL, 2000).

Ao término do abate, foram anotados os pesos de carcaça quente. As carcaças foram identificadas e mantidas em câmara fria por 24 horas à temperatura de $2^{\circ} \mathrm{C}$, após, foram pesados para se obter o rendimento de carcaça fria e a perda de umidade ao resfriamento.

As determinações químicas de matéria seca (MS), proteína bruta $(\mathrm{PB})$, extrato etéreo (EE), fibra em detergente neutro (FDN), fibra bruta (FB) e matéria mineral (MM) foram realizadas 
conforme metodologias descritas por Mizubuti et al. (2009). Os nutrientes digestíveis totais (NDT) foram estimados de acordo com a equação descrita pelo NRC (1989), onde NDT=40,26+(0,1969 x $\mathrm{PB})+(0,4228 \times \mathrm{ENN})+(1,19 \times \mathrm{EE})-(0,1379 \times \mathrm{FB})$.

Os resultados foram interpretados estatisticamente por meio de análises de variância e regressão, utilizando-se o Statistical Analyses System - SAS (1999) para nível de significância de 5\%.

Nos parâmetros de peso vivo, ganho de peso vivo, ganho médio diário e rendimento de carcaça, considerou-se cada animal como uma unidade experimental totalizando oito repetições por tratamento. Já nos dados de consumo e conversão alimentar, a unidade experimental foi a baia (com dois animais), com quatro repetições por tratamento.

Para a avaliação da análise econômica da produção de cordeiros em confinamento, neste experimento, foram considerados os preços de mercado obtidos dos ingredientes das rações, da carcaça e do peso vivo de cordeiros (CEPEA, 2010). De posse do custo de cada ração e do consumo de matéria seca das mesmas, foram calculados os resultados econômicos proporcionados pela ração.

\section{Resultados e Discussão}

Observou-se que houve efeito linear crescente $(\mathrm{P}<0,05)$ da substituição do milho grão inteiro pelos diferentes níveis de inclusão da casca de soja peletizada sobre o consumo de MS ( $\left.\mathrm{kg} \mathrm{dia}{ }^{-1}\right)$ (Tabela 3), provavelmente devido à composição da ração, e menores valores energéticos à medida que houve inclusão crescente de casca de soja na ração, bem como à maior taxa de passagem (HSU et al., 1987; NAKAMURA; OWENS, 1989). Este aumento linear no consumo de MS também pode ser devido ao reduzido tamanho de partícula; alta gravidade específica e menor densidade energética da casca de soja em relação ao milho, embora a casca de soja estivesse peletizada.

Tabela 3. Consumo de matéria seca (MS), proteína bruta (PB), fibra em detergente neutro (FDN), extrato etéreo (EE), matéria mineral (MM) e nutrientes digestíveis totais (NDT) em ovinos alimentados com diferentes níveis de substituição do milho grão inteiro por casca de soja peletizada em rações sem forragem.

\begin{tabular}{|c|c|c|c|c|c|c|}
\hline \multirow{3}{*}{$\begin{array}{l}\text { Consumo de } \\
\text { nutrientes }\end{array}$} & \multicolumn{3}{|c|}{$\begin{array}{l}\text { Rações experimentais } \\
\text { (Níveis de substituição) }\end{array}$} & \multirow{3}{*}{$\mathrm{CV}(\%)$} & \multirow{3}{*}{$\mathrm{R}^{2}$} & \multirow{3}{*}{ Regressão } \\
\hline & CS0 & CS15 & CS30 & & & \\
\hline & $0 \%$ & $15 \%$ & $30 \%$ & & & \\
\hline MS, $\mathrm{kg} \mathrm{dia}{ }^{-1}$ & 1,854 & 2,342 & 2,228 & 11,79 & 0,54 & $\hat{Y}=1,9541+0,01247 x$ \\
\hline $\mathrm{MS}, \% \mathrm{PV}$ & 3,315 & 3,834 & 3,875 & 10,08 & - & $\hat{\mathrm{Y}}=3,67$ \\
\hline MS, g PV ${ }^{0,75}$ & 0,509 & 0,603 & 0,600 & 10,42 & - & $\hat{\mathrm{Y}}=0,57$ \\
\hline $\mathrm{PB}, \mathrm{kg} \mathrm{dia}^{-1}$ & 0,199 & 0,295 & 0,281 & 12,80 & 0,61 & $\hat{\mathrm{Y}}=0,21787+0,00269 \mathrm{x}$ \\
\hline $\mathrm{PB}, \% \mathrm{PV}$ & 0,355 & 0,484 & 0,487 & 10,75 & 0,69 & $\hat{\mathrm{Y}}=0,3549+0,01274 \mathrm{x}$ \\
\hline $\mathrm{PB}, \mathrm{g} \mathrm{PV}^{0,75}$ & 0,055 & 0,076 & 0,075 & 11,19 & 0,69 & $\hat{Y}=0,0556+0,0022 x$ \\
\hline FDN, $\mathrm{kg} \mathrm{dia}^{-1}$ & 0,373 & 0,674 & 1,062 & 13,50 & 0,92 & $\hat{Y}=0,3583+0,02297 x$ \\
\hline FDN, \%PV & 0,665 & 1,103 & 1,848 & 11,84 & 0,92 & $\hat{\mathrm{Y}}=0,6138+0,0394 \mathrm{x}$ \\
\hline FDN, g PV ${ }^{0,75}$ & 0,102 & 0,173 & 0,286 & 12,17 & 0,99 & $\hat{\mathrm{Y}}=0,0954+0,0061 \mathrm{x}$ \\
\hline $\mathrm{EE}, \mathrm{g} \mathrm{dia}^{-1}$ & 74,14 & 85,82 & 64,11 & 12,18 & 0,56 & $\hat{Y}=74,135+1,891 x-0,0742 x^{2}$ \\
\hline MM, g dia ${ }^{-1}$ & 54,54 & 63,59 & 54,50 & 25,55 & - & $\hat{\mathrm{Y}}=56,54$ \\
\hline NDT, $\mathrm{kg} \mathrm{dia}^{-1}$ & 1,479 & 1,772 & 1,589 & 12,00 & - & $\hat{Y}=1,613$ \\
\hline NDT, \% PV & 2,636 & 2,901 & 2,763 & 10,40 & - & $\hat{\mathrm{Y}}=2,77$ \\
\hline NDT, g PV ${ }^{0,75}$ & 0,406 & 0,456 & 0,428 & 10,71 & - & $\hat{Y}=0,43$ \\
\hline
\end{tabular}

CS0, CS15 e CS30 correspondem às rações cujas substituições do milho inteiro pela casca de soja foram de 0,15 e $30 \%$, respectivamente. Pmáx: EE g/dia = 12,74

Fonte: Elaboração dos autores. 
Ferreira (2008), trabalhando com níveis de substituição parcial do milho por casca de soja $(0 \%, 15 \%, 30 \%$ e $45 \%)$ para ovinos confinados recebendo dietas contendo $10 \%$ de volumoso, também encontrou aumento linear crescente no consumo de matéria seca $\left(\mathrm{kg} \mathrm{dia}^{-1}\right.$ e g kg PV $\left.{ }^{0,75}\right)$. Da mesma forma, o aumento no consumo de MS de rações semelhantes ao do presente experimento foi encontrado por Katsuki (2009), trabalhando com bovinos recebendo níveis crescentes de inclusão de casca de soja $(0 \% ; 15 \%$ e $30 \%)$ em rações a base de milho inteiro sem utilização de volumosos e atribuiu este fato ao aumento na taxa de passagem da ração causado pela casca de soja.

Não foi encontrada diferença significativa no consumo de MS em relação ao peso vivo e tamanho metabólico $(\mathrm{P}>0,05)$, cujos resultados são semelhantes àqueles encontrados por Gilaverde (2009), em experimento com substituição parcial e total do milho por casca de soja, em ovinos confinados, recebendo rações com $89 \%$ de concentrado na ração total.

Observou-se efeito linear crescente $(\mathrm{P}<0,05)$ das diferentes rações sobre o consumo de PB (kg dia $^{-1}, \% \mathrm{PV}$ e $\mathrm{PV}^{0,75}$ ) e de FDN (Tabela 3), provavelmente devido ao aumento no consumo de matéria seca $\left(\mathrm{kg} \mathrm{dia}{ }^{-1}\right)$ conforme houve a substituição crescente do milho pela casca de soja. O aumento no consumo de FDN também ocorreu devido ao maior teor de FDN nas rações experimentais à medida que houve substituição do milho pela casca de soja (Tabela 2).

Os níveis crescentes de concentrado alteraram o consumo de EE g dia ${ }^{-1}$ de maneira quadrática com ponto de máximo para o nível de substituição do milho pela CS em 12,74\%. Provavelmente houve seleção de ingredientes no momento da alimentação dos animais, que podem ter preferido, a um determinado momento, se alimentar preferentemente de milho. (VAN SOEST, 1987; VIEIRA; QUEIROZ; HENRIQUE, 1994). Este fato foi observado durante o período experimental.

Os níveis crescentes de substituição do milho inteiro pela casca de soja promoveram efeito quadrático $(\mathrm{P}<0,05)$ sobre o peso vivo final e ganho médio diário (Tabela 4), sendo o ponto de máxima encontrada para os níveis de substituição em $14,78 \%$ e $13,06 \%$, respectivamente. Provavelmente, houve alteração do padrão de fermentação ruminal causado pela inclusão de casca de soja na ração, que diminui a quantidade de carboidrato não estrutural e amido no rúmen. A substituição do milho pela casca de soja pode ter provocado aumento da relação acetato:propionato como resultado da fermentação ruminal, com consequente diminuição na produção de ácido lático e diminuição de riscos de acidose ruminal (PORDOMINGO et al., 2002). Além de modificar os produtos da fermentação ruminal, a substituição do milho pela casca de soja ao redor de $15 \%$ pode ter atendido a quantidade mínima de fibra efetiva necessária para o estimulo da ruminação, causada pelo grão de milho inteiro, neste tipo de ração.

Quando a casca de soja peletizada substituiu $30 \%$ do milho inteiro verificou-se o menor ganho de peso dos animais comparado aos demais tratamentos. Este menor desempenho pode estar relacionado à diminuição da fibra efetiva da ração total, com consequente diminuição na ruminação e tamponamento ruminal, pois segundo o NRC (2007), apenas 2\% da FDN da casca de soja é efetiva. Outro fator que pode justificar o pior desempenho animal quando $30 \%$ de casca de soja substituiu o milho é o fato de a ração total possuir a menor quantidade de nutrientes digestíveis totais. 
Tabela 4. Peso vivo inicial em jejum (PVI), peso vivo final em jejum (PVF), ganho médio diário (GMD) e conversão alimentar (CA) em cordeiros recebendo diferentes níveis de substituição do milho inteiro por casca de soja peletizada em rações sem forragem.

\begin{tabular}{lcccccc}
\hline \multirow{2}{*}{ Característica } & \multicolumn{3}{c}{ Inclusão de casca de soja } & \multirow{2}{*}{ CV\% } & \multirow{2}{*}{ R2 } & \multirow{2}{*}{ Regressão } \\
\cline { 2 - 4 } & $0 \%(\mathrm{CS} 0)$ & $15 \%(\mathrm{CS} 15)$ & $30 \%(\mathrm{CS} 30)$ & & & \\
\hline PVI, kg & 22,40 & 23,65 & 24,00 & 14,34 & - & $\hat{\mathrm{Y}}=23,35$ \\
PVF, kg & 33,63 & 37,39 & 33,40 & 11,38 & 0,22 & $\hat{\mathrm{Y}}=33,62+0,509 \mathrm{x}-0,0172 \mathrm{x}^{2}$ \\
GMD, kg dia ${ }^{-1}$ & 0,267 & 0,327 & 0,224 & 25,22 & 0,29 & $\hat{\mathrm{Y}}=0,267+0,094 \mathrm{x}-0,0036 \mathrm{x}^{2}$ \\
$\mathrm{CA}, \mathrm{kg} \mathrm{MS} / \mathrm{kg}$ PV & 3,51 & 3,62 & 5,16 & 18,43 & 0,80 & $\hat{\mathrm{Y}}=3,2663+0,0551 \mathrm{x}$ \\
\hline
\end{tabular}

CS0, CS15 e CS30 correspondem às rações cujas substituições do milho inteiro pela casca de soja foram de 0,15 e $30 \%$, respectivamente.

Pmáx.: PVF $(\mathrm{kg})=14,78 \%$; GPMD $=13,06 \%$

Fonte: Elaboração dos autores.

Turino et al. (2007) testando níveis crescentes de FDN em rações $(0,14$ e 18\%) contendo 0\%, $5 \%, 10 \%$ de bagaço de cana in natura (BIN) e $7,8 \%$ e $11,9 \%$ de casca de soja encontraram valores de 220,$67 ; 237,33,202,37$ e $246,67,258,17 \mathrm{~g}$ dia $^{-1}$, respectivamente, de ganho médio diário e concluíram que a casca de soja pode ser utilizada como fonte de fibra para cordeiros terminados com dietas contendo alta proporção de concentrado. Atribuíram ainda o melhor desempenho dos cordeiros alimentados com a casca de soja à melhor digestibilidade da MS e maior aporte de nutrientes disponibilizados para o crescimento dos animais.

Ao se derivar a equação de regressão para peso vivo final verificou-se que o peso vivo máximo será maior ao redor de $14,78 \%$ de substituição, onde seria encontrado $37,39 \mathrm{~kg}$ de peso vivo final. Para ganho médio diário, $13,08 \%$ de inclusão de casca de soja promoveria $328,88 \mathrm{~g} \mathrm{dia}^{-1}$ de desempenho em cordeiros alimentados com ração completa a base de milho inteiro.

Observa-se que houve efeito linear crescente $(\mathrm{P}<0,05)$ dos diferentes níveis de casca de soja na ração sobre a conversão alimentar (CA). Para os níveis de 0 e $15 \%$ de substituição, os valores foram semelhantes aos encontrados por Turino et al. (2007), que avaliaram a substituição da fibra em detergente neutro (FDN) do bagaço de canade-açúcar in natura (BIN) pela FDN da casca de soja (CS), sobre o desempenho de cordeiros da raça Santa Inês, e encontraram valores de 3,$89 ; 3,68 ; 3,93 ; 3,50$ e 3,59 para conversão alimentar referentes aos tratamentos de $100 \%$ concentrado, $5 \%$ BIN, $10 \%$ BIN, 8 CS e $12 \% \mathrm{CS}$, respectivamente.

Ferreira et al. (2008), substituindo 0\%; 15\%; $30 \%$ e $45 \%$ do milho por casca de soja em rações contendo $90 \%$ de concentrado para terminação de cordeiros, sendo que $70 \%$ da ração total no tratamento controle era composta por milho, não encontraram diferença significativa para ganho médio diário $\left(0,281 \mathrm{~kg} \mathrm{dia}^{-1}\right)$. Entretanto, o consumo de matéria seca aumentou linearmente conforme a casca de soja foi inclusa nas rações, com consequente piora na conversão alimentar (3,51; 3,$71 ; 3,81$ e 3,98 , respectivamente). Os autores atribuíram este aumento no consumo de matéria seca e consequente piora na conversão alimentar à maior taxa de passagem das rações com maiores quantidades de casca de soja e à menor densidade energética da mesma.

A pior conversão alimentar foi encontrada quando $30 \%$ de casca de soja substituiu o milho inteiro na ração, visto que houve menor ganho médio diário e maior consumo de matéria seca $(\mathrm{kg}$ dia $\left.^{-1}\right)$ neste tratamento. Esta pior conversão de 5,16 pode ser considerada inadequada para cordeiros confinados, baseados nos dados encontrados em 
literatura, cujos valores estão situados entre 3,50 e 4,45 em animais alimentados com rações contendo mais de $80 \%$ de concentrado em sua composição (FERREIRA, 2008; TURINO et al., 2007;
PEREIRA, 2008).

Não foram encontradas diferenças significativas $(\mathrm{P}>0,05)$ nas características de carcaça avaliadas neste trabalho (Tabela 5).

Tabela 5. Peso de carcaça quente (PCQ), peso de carcaça fria (PCF), rendimento de carcaça quente (RCQ), rendimento de carcaça fria (RCF) e perda por resfriamento (PR) de cordeiros recebendo diferentes níveis de substituição do milho inteiro por casca de soja peletizada em rações sem forragem.

\begin{tabular}{|c|c|c|c|c|c|c|c|}
\hline \multirow{2}{*}{ Característica } & \multicolumn{3}{|c|}{ Inclusão de casca de soja } & \multirow{2}{*}{$\mathrm{CV} \%$} & \multirow{2}{*}{ Regressão } & \multicolumn{2}{|c|}{ Sexo } \\
\hline & $0 \%(\mathrm{CS} 0)$ & $15 \%(\mathrm{CS} 15)$ & $30 \%(\mathrm{CS} 30)$ & & & $\mathrm{F}$ & $\mathrm{M}$ \\
\hline PCQ, kg & 17,57 & 19,26 & 17,375 & 11,98 & $\hat{Y}=18,07$ & 18,08 & 18,07 \\
\hline PCF kg & 16,99 & 18,62 & 16,806 & 12,11 & $\hat{\mathrm{Y}}=17,47$ & 17,52 & 17,43 \\
\hline RCQ \% & 52,33 & 51,42 & 52,11 & 5,13 & $\hat{\mathrm{Y}}=51,95$ & 51,85 & 52,06 \\
\hline RCF \% & 50,60 & 49,71 & 50,4 & 5,18 & $\hat{\mathrm{Y}}=50,24$ & 50,24 & 50,24 \\
\hline PR \% & 3,320 & 3,33 & 3,28 & 13,09 & $\hat{\mathrm{Y}}=3,31$ & $3,12 \mathrm{a}$ & $3,5 \mathrm{~b}$ \\
\hline
\end{tabular}

CS0, CS15 e CS30 correspondem às rações cujas substituições do milho inteiro pela casca de soja foram de 0 , 15 e $30 \%$, respectivamente.

a,b Medias seguidas de letras diferentes, diferem ao nível de 5\% de probabilidade.

Fonte: Elaboração dos autores.

Os valores encontrados no rendimento de carcaça quente (RCQ) foram superiores aos encontrados por Hejazi, Fluharty e Perley (1999); Santos (1999) e Turino et al. (2007) que encontraram valores médios de 50,3\%, 47,5\% e 47,4\%, respectivamente, para cordeiros Targhee/ Polypay, Santa Inês/Bergamácia e Santa Inês. O maior rendimento de carcaça encontrado neste experimento pode estar ligado ao grupo genético da raça Texel, especializada em produção de carne, e possivelmente ao menor conteúdo e tamanho ruminal dos animais alimentados com rações contendo alto teor de concentrados, sem forragem.

Valores de perda por resfriamento também não diferiram estatisticamente entre os tratamentos e foram semelhantes aos descritos por Hejazi, Fluharty e Perley (1999) que encontraram valores de $3,06 \%$, testando diferentes fontes de fibras e processamentos do milho em rações com alto teor de concentrado, sem utilização de fibra longa. Resultados melhores de perda por resfriamento foram encontrados por Turino et al. (2007), que avaliaram níveis de $0 \%, 7,8 \%$ e $11,9 \%$ de inclusão de casca de soja em rações a base de concentrados, sem uso de fibra longa, para cordeiros e encontraram, respectivamente, valores de 2,56\%, $2,14 \%$ e $2,27 \%$.

Não foram encontradas diferenças significativas entre sexos para as características de PCQ, PCF, RCQ e RCF. Porém, foram encontradas diferenças significativas para perda por resfriamento, provavelmente pela maior deposição de gordura na carcaça das fêmeas. Quando a fase final do crescimento ocorre em confinamento, os animais de maturidade precoce, especialmente as fêmeas, atingem rapidamente a maturidade ocorrendo maior deposição de energia em forma de gordura (SAINZ, 2000).

Pode-se observar que houve uma diminuição no custo por quilo de matéria seca das rações à medida que se substituiu o milho pela casca de soja (Tabela $6)$. 
Tabela 6. Médias dos custos de alimentação, das receitas e da avaliação econômica da produção de cordeiros em confinamento recebendo diferentes níveis de substituição do milho inteiro por casca de soja peletizada em rações sem forragem.

\begin{tabular}{|c|c|c|c|}
\hline \multirow[t]{2}{*}{ Item } & \multicolumn{3}{|c|}{ Rações experimentais } \\
\hline & CS0 $(0 \%)$ & CS15 (15\%) & CS30 (30\%) \\
\hline Custo/kg MS da ração $(\mathrm{R} \$)^{1}$ & 0,51 & 0,50 & 0,49 \\
\hline Custo/kg MS da ração (US\$) ${ }^{5}$ & 0,30 & 0,29 & 0,29 \\
\hline Preço inicial/animal (R\$3,50/kg PV) & 78,40 & 82,78 & 84,00 \\
\hline Preço inicial/animal (US\$) & 46,39 & 48,98 & 49,70 \\
\hline Custo diário da alimentação ( $\mathrm{R} \$)$ & 0,47 & 0,59 & 0,57 \\
\hline Custo diário (US\$) & 0,28 & 0,35 & 0,34 \\
\hline Custo da alimentação no período (R\$) & 19,93 & 24,69 & 23,88 \\
\hline Custo da alimentação no periodo (US\$) & 10,06 & 11,02 & 9,94 \\
\hline Receita bruta final/animal ( $\mathrm{R} \$ 8,00 / \mathrm{kg}$ carcaça) & 135,95 & 149,00 & 134,45 \\
\hline Receita bruta final/animal (US\$) & 80,44 & 88,17 & 79,56 \\
\hline Lucro/animal (R\$) & 37,62 & 41,54 & 26,57 \\
\hline Lucro/animal (US\$) & 22,26 & 24,58 & 15,72 \\
\hline Custo/kg PV produzido (R $\$)^{2}$ & 1,78 & 1,80 & 2,54 \\
\hline Custo/kg PV produzido (US\$) & 3,96 & 4,58 & 3,41 \\
\hline Custo/kg carcaça produzido $(\mathrm{R} \$)^{4}$ & 2,98 & 3,19 & 4,14 \\
\hline Custo/kg carcaça produzido (US\$) & 1,76 & 1,89 & 2,45 \\
\hline
\end{tabular}

CS0, CS15 e CS30 correspondem às rações cujas substituições do milho inteiro pela casca de soja foram de 0 , 15 e $30 \%$, respectivamente.

${ }^{1} \mathrm{O}$ custo das rações foram calculados considerando o preço do milho a $\mathrm{R} \$ 0,30 / \mathrm{kg}$; da casca de soja a $\mathrm{R} \$ 0,25 / \mathrm{kg}$ e o concentrado a R\$ $1,30 / \mathrm{kg}$.

${ }^{2} \mathrm{O}$ custo/kg de ganho de PV foi obtido pela multiplicação da conversão alimentar pelo custo das rações.

${ }^{3}$ A quantidade de carne produzida foi calculada pela diferença entre o peso da carcaça resfriada e peso de carcaça inicial. Para o peso inicial admitiu-se o rendimento $46 \%$.

${ }^{4} \mathrm{O}$ custo/kg de carne produzida foi obtido pela divisão do custo total pela quantidade de $\mathrm{kg}$ de carne produzido.

${ }^{5}$ Valor do dólar relativo ao mês de setembro de $2010=\mathrm{R} \$ 1,69$.

Fonte: Elaboração dos autores.

Entretanto, no que se refere ao custo médio diário da alimentação, houve um aumento quando $15 \%$ de casca de soja substituiu o milho inteiro nas rações experimentais, provavelmente pelo aumento no consumo de matéria seca (Tabela 3 ) com consequente aumento no custo alimentar no período total de confinamento. Ferreira et al. (2008), trabalharam com cordeiros em confinamento recebendo rações com $90 \%$ de concentrado e $10 \%$ de volumoso, sendo que o milho entrou em $70 \%$ do concentrado e foi substituído pela casca de soja em $0 ; 15 ; 30$ e 45\%, e relataram que a substituição crescente do milho por casca de soja reduziu linearmente o custo do quilograma de matéria seca da ração.

Os custos por quilograma de peso vivo e de carcaça produzidos podem ser parâmetros importantes para avaliação da eficiência econômica e produtiva do sistema de confinamento, pois não consideram a valorização do preço entre compra e venda do cordeiro, além de variáveis como peso inicial e final dos animais. Neste trabalho foi observado que, apesar do menor custo do quilo da ração com níveis crescentes de inclusão de casca de soja, houve aumento no valor do quilo de carne produzida. Este fato pode ser explicado pelo valor 
da conversão alimentar em animais submetidos aos tratamentos que continham casca de soja.

Quando se substituiu o milho inteiro por 30\% da casca de soja, ocorreu a pior conversão alimentar e menor lucro por animal ( $\$$ 26,57). Por outro lado, quando $15 \%$ de casca de soja substituiu o milho inteiro, foi observado maior lucro por animal (R\$ $41,57)$ sendo que este melhor resultado financeiro pode estar ligado ao maior ganho de peso durante o confinamento, resultando em carcaças mais pesadas ao abate e maior valor de venda por animal.

Trabalhando com rações contendo $50 \%$ de volumoso e $50 \%$ de concentrado, onde o fubá de milho foi substituído por casca de soja nos níveis de 0, 25, 50 e 75\%, para cordeiros em confinamento, Santos et al. (2008) relataram custos de R\$ 0,21 por quilograma de matéria seca da alimentação e receita de $\mathrm{R} \$ 26,53$ por animal. Estes resultados podem indicar que, apesar do menor custo diário das rações com maior quantidade de volumoso, rações contendo maior quantidade de alimentos concentrados pode ser uma alternativa viável podendo apresentar maior lucratividade na engorda de cordeiros em confinamento.

Para que a inclusão da casca de soja em substituição ao milho inteiro, nas rações sem fibra longa, para terminação de cordeiros em confinamento, seja viável, é necessário avaliar o preço de compra do milho e da casca de soja, bem como o efeito do nível de substituição sobre o desempenho produtivo dos animais.

\section{Conclusões}

A substituição crescente do milho grão inteiro por casca de soja peletizada na ração de cordeiros em confinamento promove aumento do consumo de matéria seca, proteína bruta, fibra em detergente neutro e extrato etéreo, pelos animais.

Casca de soja peletizada na proporção de quinze por cento em substituição ao milho grão inteiro, em rações sem fibra longa, proporciona aumento no ganho médio diário e no lucro da engorda de cordeiros em confinamento.

A utilização de até trinta por cento de casca de soja em substituição ao milho inteiro na ração de cordeiros não influencia negativamente as características de carcaça.

\section{Referências}

BRASIL. Ministério Pecuária e Abastecimento. Instrução normativa n.3, de 17 de Janeiro de 2000. Diário Oficial [da] União, Brasília, DF, 24 jan. 2000, Seção 1, p. 14.

CENTRO DE ESTUDOS AVANÇADOS EM ECONOMIA APLICADA - CEPEA (ESALQ/USP). Indicador de preços. Piracicaba, SP. 2010. Disponível em: $<$ http://www.cepea.esalq.usp.br $>$. Acesso em: 15 jul. 2010 .

FERREIRA, E. M. Substituição parcial do milho pela casca de soja na alimentação de cordeiros da raça Santa Inês em confinamento. 2008.Tese (Dissertação de Mestrado em Agronomia) - Universidade de São Paulo, Escola Superior de Agricultura Luiz de Queiróz, Piracicaba.

FERREIRA, E. M.; PIRES, A. V.; SUSIN, I.; MENDES, C. Q.; ARAUJO, R. C.; QUEIROZ, M. A. A.; URANO, F. S.; GENTIL, R. S.; AMARAL, R. C.; GILAVERTE, S. Effects of replacing corn of soybean hulls on aparent digestibility of nutrients and ruminal parameters in lambs. Indianápolis: ADSA-ASAS Annual Meeting, 2008. 500 p.

GADIENT, M. Effect of pelleting on nutritional quality of feed. In: Proceedings of Mariland Nutritional Conference, College Park, MD. University of Maryland, College Park, 1986. p. 73-79.

GILAVERDE, S. Substituição milho por polpa citrica peletizada ou casca de soja na alimentação de borregas. 2009. Tese (Dissertação de Mestrado em Agronomia) - Universidade de São Paulo, Escola Superior de Agricultura Luiz de Queiróz, Piracicaba.

HEJAZI, S.; FLUHARTY, F. L.; PERLEY, J. E. Effect of corn processing and dietary fiber source on feedlot performance, visceral organ weight, diet digestibility and nitrogen metabolism in lambs. Journal of Animal Science, Champaign, v. 77, n. 1, p. 507-515, 1999.

HSU, J. T.; FAULKNER, D. B.; GARLEB, K. A.; BARCLAY, R. A.; FAHEY, G. C. J.; BERGER, L. L. Evaluation of corn fiber, cottonseed hulls, oat hulls and 
soybean hulls as roughage sources for ruminants. Journal of Animal Science, Champaign, v. 65, n. 1, p. 244-255, 1987.

KATSUKI, P. A. Avaliação nutricional, desempenho e qualidade da carne de bovinos alimentados com rações sem forragem, com diferentes niveis de substituição do milho inteiro por casca de soja. 2009. Tese (Doutorado em Ciência Animal) - Universidade Estadual de Londrina, Londrina.

LUDDEN, P. A.; CECAVA, M. J.; HENDRIX, K. S. The value of soybeans hulls as a replacement for corn in beef cattle diets formulated with or without added fat. Journal of Animal Science, Champaign, v. 73, n. 9, p. 2706-2711, 1995.

MIZUBUTI, I. Y; PINTO, A. P.; RAMOS, B. M. O.; PEREIRA, E. S. Métodos laboratoriais de avaliação de alimentos para animais. Londrina: EDUEL, 2009. 228 p.

NAKAMURA, T.; OWENS, F. G. High amounts of soyhulls for pelleted concentrate diets. Journal of Dairy Science, Champaign, v. 72, n. 4, p. 988-994, 1989.

NATIONAL RESEARCH COUNCIL - NRC. Nutrient requeriments of dairy cattle. $6^{\text {th }}$ rev. ed. Washington, D. C.: NEC, 1989. 157 p.

Nutrient requirements of sheep. Washington, D. C.: National Academy Press, Sixth Revised Edition, 1985. $99 \mathrm{p}$.

. Nutrient requirements of small ruminants: sheep, goats, cervids, and new world camelids. Washington, D. C.: National Academy Press, 2007. 292 p.

PEREIRA, M. S.; RIBEIRO, E. L. A.; MIZUBUTI, I. Y.; ROCHA, M. A.; KURAOKA, J. T.; NAKAGHI, E. Y. O. Consumo de nutrientes e desempenho de cordeiros em confinamento alimentados com dietas com polpa cítrica úmida prensada em substituição à silagem de milho. Revista Brasileira de Zootecnia, Viçosa, MG, v. 37, n. 1, p. 134-139, 2008.
PORDOMINGO, A. J.; JONAS, O.; ADRA, M.; JUAN, N. A.; AZCÁRATE, M. P. Evaluación de dietas basadas en grano entero, sin fibra larga, para engorde de bovinos a corral. RIA-Revista de Investigaciones Agropecuarias, INTA, Argentina, v. 31, n. 1, p. 1-22, 2002.

SAINZ, R. D. Avaliação de carcaças e cortes comerciais de carne caprina e ovina. In: SIMPÓSIO INTERNACIONAL SOBRE CAPRINOS E OVINOS DE CORTE, 1., 2000, João Pessoa. Anais... João Pessoa: [s. n.], 2000. p. 237-250.

SANTOS, C. L. Estudo do desempenho, das características da carcaça e do crescimento alométrico de cordeiros das raças Santa Inês e Bergamácia. 1999. Dissertação (Mestrado em Zootecnia) - Universidade Federal de Lavras, Lavras.

SANTOS, J. W.; CABRAL, L. S.; ZERVOUDAKIS, J. T.; SOUZA, A. L.; ABREU, J. G.; BAUER, M. O. Casca de soja em dietas para ovinos. Revista Brasileira de Zootecnia, Viçosa, MG, v. 37, n. 11, p. 2049-2055, 2008.

STATISTICAL ANALYSES SYSTEM - SAS. User's guide. Version 6. 12. SAS, 1999. v. 1.

TURINO, V. F.; SUSIN, I.; PIRES, A. V.; MENDES, C. Q.; MORAIS, J. B.; OLIVEIRA, R. C. J. Casca de soja na alimentação de cordeiros confinados: desempenho e características da carcaça. Ciência Animal Brasileira, Goiania, v. 8, n. 3, p. 495-503, 2007.

VAN SOEST, P. J. Interaction of feeding behavior and forage composition. In: International Conference on Goats, 4., 1987, Brasília. Proceedings... Brasília: EMBRAPA, 1987. p. 971-987.

VIEIRA, R. A. M.; QUEIROZ, A. C.; HENRIQUE, D. S. Nutritional ecology of the ruminant. $2^{\text {th }}$ ed. Ithaca: Cornell University Press, 1994. 476 p.

ZAMBOM, M. A.; SANTOS, G. T.; MODESTO, E. C.; ALCALDE, C. R.; GOLÇALVES, G. D.; SILVA, D. C.; SILVA, K. T.; FAUSTINO, J. O. Valor nutricional da casca do grão de soja, farelo de soja, milho moído e farelo de trigo para bovinos. Acta Scientiarum, Maringá, v. 23, n. 4, p. 937- 943, 2001. 
